Article

\title{
Durability and Abrasion Resistance of Innovative Recycled Pervious Concrete with Recycled Coarse Aggregate of Different Quality under Sulfate Attack
}

\author{
Minqi Hua ${ }^{1,2} \mathbb{C}$, Bo Chen ${ }^{2, *}$, Yun Liu ${ }^{3}$, Hui Liu ${ }^{1,3}, * \mathbb{C}$, Pinghua Zhu ${ }^{3}$, Chunhong Chen ${ }^{3}$ and Xinjie Wang ${ }^{3}$ \\ 1 State Key Laboratory of Silicate Materials for Architectures, Wuhan University of Technology, \\ Wuhan 430070, China; alcestle@gmail.com \\ 2 School of Civil Engineering and Architecture, Wuhan University of Technology, Wuhan 430070, China \\ 3 Department of Civil Engineering, Changzhou University, Changzhou 213164, China; \\ cczuliuyun@gmail.com (Y.L.); zph@cczu.edu.cn (P.Z.); chench@cczu.edu.cn (C.C.); \\ wangxinjie@cczu.edu.cn (X.W.) \\ * Correspondence: cebchen@whut.edu.cn (B.C.); liuhui@cczu.edu.cn (H.L.)
}

check for updates

Citation: Hua, M.; Chen, B.; Liu, Y.; Liu, H.; Zhu, P.; Chen, C.; Wang, X. Durability and Abrasion Resistance of Innovative Recycled Pervious Concrete with Recycled Coarse Aggregate of Different Quality under Sulfate Attack. Appl. Sci. 2021, 11, 9647. https://doi.org/10.3390/ app11209647

Academic Editor: Carlos Thomas

Received: 18 September 2021

Accepted: 11 October 2021

Published: 15 October 2021

Publisher's Note: MDPI stays neutral with regard to jurisdictional claims in published maps and institutional affiliations.

Copyright: (c) 2021 by the authors. Licensee MDPI, Basel, Switzerland. This article is an open access article distributed under the terms and conditions of the Creative Commons Attribution (CC BY) license (https:// creativecommons.org/licenses/by/ $4.0 /)$.

\begin{abstract}
Construction and demolition wastes (C\&DWs) have raised a large number of ecological and environmental problems. Recycling C\&DWs into arecycled concrete aggregate (RCA) will help save natural resources effectively and reduce the negative impact of C\&DW on the environment. Innovative pervious concrete (IPC) can mitigate extreme weather disasters, such as rainstorms, and overcome the low strength and poor durability of traditional pervious concrete. In this study, innovative recycled pervious concrete (IRPC) is prepared by combining RCA with IPC, which has broad application prospects and ecological friendliness. This study investigates the effect of RCA quality grades and replacement rates on the mechanical property, permeability, sulfate resistance and abrasion resistance of IRPC. IRPC mixtures were prepared with three different quality grades (high, medium and low qualities) of aggregates named as $\mathrm{NA}, \mathrm{RCA}_{1}$ and $\mathrm{RCA}_{2}$. Moreover, the replacement rate of RCA for NA varied as $0 \%, 25 \%, 50 \%, 75 \%$ and $100 \%$. The IRPC specimens were tested for compressive strength, mass loss and abrasion resistance after different sulfate wetting-drying cycles of 0,30 and 60 . The results exhibited that the initial compressive strength of all types of IRPC was more than $40 \mathrm{MPa}$. The compressive strength and mass of most IRPC increased first and then decreased slightly with the passage of a number of sulfate wetting-drying cycles, indicating IRPC has good resistance to sulfate attack. Sulfate attack and the addition of RCA will reduce the abrasion resistance of IRPC. However, when the replacement rate is lower than 50\%, and the RCA quality is better (attached mortar content $<25 \%$ ), the abrasion resistance of IRPC will be improved under sulfate attack. The experimental results might be useful as a reference and design methodology for employing IRPC in pavement applications in the future.
\end{abstract}

Keywords: innovative recycled pervious concrete; recycled aggregate; quality grades of aggregate; replacement rate; abrasion resistance; sulfate attack

\section{Introduction}

With the acceleration of urbanization, the whole world is facing with shortage of natural aggregate (NA) and increasing and haphazard piles of construction and demolition wastes (C\&DWs) [1,2]. In order to deal with the continuous destruction and pollution to the environment caused by the above problems, one of the possible solutions is to recycle C\&DWs into a recycled concrete aggregate (RCA) [3,4]. Using RCA instead of NA will help save natural resources effectively and reduce the negative impact of C\&DWs on the environment $[5,6]$. Therefore, the utilization of RCA has been widely promoted all over the world [7]. On the other hand, extreme weather occurs frequently around the world, and extraordinary rainstorm brings serious waterlogging to cities, which affects economic 
development and social life [8]. Compared with traditional impervious pavement, pervious concrete pavement can reduce rainwater runoff, reduce noise, replenish groundwater, reduce the heat island effect and remove rainwater runoff pollutants $[9,10]$. However, the low strength, high likelihood for clogging and poor durability of traditional pervious concrete limit its potential use in structural applications [11,12]. In order to solve these defects, a kind of innovative pervious concrete with top-bottom interconnected pores was designed and prepared by our former research [13]. The results prove that innovative pervious concrete is superior to traditional pervious concrete in mechanical properties and frost resistance. The environmental friendliness of innovative pervious concrete can be further improved by replacing NA with RCA. However, whether it has adverse effects on mechanical properties and durability of innovative recycled pervious concrete (IRPC) remains to be studied.

In general, the utilization of RCA will contribute to the degradation of mechanical properties and the durability of recycled concrete [14-16]. Replacing NA with RCA will lead to a decrease in compressive strength of the concrete, which will continue to decrease with the increase of the replacement rate of RCA [17-19]. Moreover, the quality grades of RCA, such as water absorption, crushing index and attached mortar content, play an important role in the durability of recycled concrete [20]. Furthermore, the strength and durability of recycled concrete are affected by the interfacial transition zone (ITZ), as it owns many cracks and pores, low bonding strength and high permeability [21]. Especially for the traditional recycled pervious concrete, only the very thin layers of cement paste are used as the binder between its aggregates [22], which causes the mechanical properties to often depend approximately on the strength of ITZ. EL-Hassan et al. [23] found that the mechanical properties and abrasion resistance were negatively affected due to the poor ITZ in traditional recycled pervious concrete. Vieira et al. [17] observed the decrease of mechanical properties of pervious concrete with the increase of RCA replacement. These studies showed that the maximum compressive strength of traditional recycled pervious concrete was less than $10 \mathrm{MPa}$, and when the RCA replacement rate exceeded $70 \%$, the compressive strength decreased sharply and approximately had no strength anymore. However, IRPC is prepared by reserving top-bottom interconnected pores in advance in the concrete matrix, which makes its initial compressive strength and durability much higher than traditional ones.

Various durability factors, such as chloride ion erosion, sulfate attack and vehicle abrasion, will occur in the practical use of IRPC. Coastal and inland saline regions are rich in caustic ions, such as sulfate ions [24], which will make IRPC exposed to corrosive environments and more susceptible to potential durability problems $[25,26]$. Sulfate attack is one of the most common types of corrosion and can lead to serious internal expansion failure, strength degradation and durability problems of concrete [26]. The external sulfate ions penetrate into the concrete and react with the dissolved calcium hydroxide to form gypsum, and further react with the hydration aluminate products of cement paste to form ettringite [27]. The volume of ettringite grows inside the pores of the concrete, and then the expansive stress is exerted on the pore wall, causing micro-cracking and damage to the concrete [27]. In addition, IRPC pavements are worn by passing vehicles, which could be exacerbated under sulfate attacks. Therefore, it is worth studying the durability and abrasion resistance of IRPC under sulfate attack, but it is not receiving enough attention right now.

This research aims to investigate the feasibility of using RCA with the innovative pervious concrete to prepare IRPC. Three different quality grades (high, medium and low qualities) and five different replacement rates $(0 \%, 25 \%, 50 \%, 75 \%$ and $100 \%)$ of RCA were analyzed. The compressive strength, permeability coefficient and abrasion resistance of IRPC under different sulfate wetting-drying cycles (0,30 and 60) were discussed. The variations of the ITZ of IRPC after sulfate attack were characterized by SEM. The obtained experimental results and data would be beneficial for future applications of the utilization of IRPC in pavement engineering. 


\section{Experimental}

\subsection{Materials}

Ordinary Portland cement of type P.O 42.5 produced by Jiangsu Yangzi Cement Company, fly ash (FA) and silica fume (SF) were used as binding materials to prepare IRPC. The chemical compositions of these binding materials were listed in Table 1. Natural river sand with a fineness modulus of 2.4 was used as the fine aggregate. Polycarboxylate type superplasticizer (SP) was used as the water-reducing agent in the IRPC preparation process.

Table 1. Chemical compositions of binding materials. (wt.\%).

\begin{tabular}{ccccccccccc}
\hline & $\mathbf{C a O}$ & $\mathrm{SiO}_{2}$ & $\mathbf{A l}_{\mathbf{2}} \mathbf{O}_{\mathbf{3}}$ & $\mathbf{F e}_{\mathbf{2}} \mathbf{O}_{\mathbf{3}}$ & $\mathbf{S O}_{\mathbf{3}}$ & $\mathbf{M g O}$ & $\mathbf{K}_{\mathbf{2}} \mathbf{O}$ & $\mathrm{TiO}_{\mathbf{2}}$ & $\mathbf{M n O}$ & $\mathbf{L O I}^{\mathbf{a}}$ \\
\hline Cement & 61.03 & 20.41 & 7.42 & 3.74 & 2.06 & 1.26 & 0.75 & 0.28 & 0.15 & 1.39 \\
FA & 3.72 & 51.50 & 29.33 & 3.77 & 1.69 & 1.16 & 1.70 & 0.98 & 1.16 & 1.18 \\
SF & 0.28 & 87.04 & 1.13 & 0.98 & 0.85 & 0.87 & - & - & 0.13 & 0.86 \\
\hline
\end{tabular}

a LOI: Loss on ignition.

Since the different types of RCA for practical application varied in their quality. In order to explore the effect of RCA quality grades, three different quality grades of coarse aggregate were used in this study. Natural limestone aggregate, which can approximately be regarded as high-quality RCA, was used as the control group and compared to two other types of aggregate. Medium-quality RCA, marked as $\mathrm{RCA}_{1}$, was prepared by crushing and sieving the waste concrete samples from the laboratory. Low-quality RCA, marked as $\mathrm{RCA}_{2}$, was provided by Jiangsu lvhe Environmental Technology CO. LTD. The particle sizes of the three kinds of aggregates range from 4.75 to $9.5 \mathrm{~mm}$. The physical properties and macro photographs of the three coarse aggregates were displayed in Table 2 and Figure 1, respectively. It is obvious that NA has the best performance in all aspects and can be regarded as the high-grade aggregate. The attached mortar can be clearly observed on the surface of $\mathrm{RCA}_{1}$. Due to the existence of attached mortar, its performance is slightly inferior to NA. $R C A_{1}$ is regarded as the medium-grade aggregate. $\mathrm{RCA}_{2}$ not only possesses a large amount of attached mortar on the surface but also contains complex aggregate composition. It is evident that $\mathrm{RCA}_{2}$ is mixed with red bricks, which greatly affects its performance. Therefore, $\mathrm{RCA}_{2}$ has the worst performance and is regarded as the low-grade aggregate.

Table 2. Physical properties of the coarse aggregates.

\begin{tabular}{ccccc}
\hline $\begin{array}{c}\text { Aggregate } \\
\text { Types }\end{array}$ & $\begin{array}{c}\text { Apparent } \\
\text { Density }\left(\mathbf{k g} / \mathbf{m}^{\mathbf{3}}\right)\end{array}$ & $\begin{array}{c}\text { Water Absorption } \\
\text { at 24 h (\%) }\end{array}$ & $\begin{array}{c}\text { Crushing } \\
\text { Index (\%) }\end{array}$ & $\begin{array}{c}\text { Attached Mortar } \\
\text { Content (\%) }\end{array}$ \\
\hline NA & 2703 & 1.8 & 5.3 & - \\
RCA & 2621 & 3.1 & 12.4 & 24.2 \\
RCA $_{2}$ & 2543 & 6.6 & 16.1 & 41.6 \\
\hline
\end{tabular}

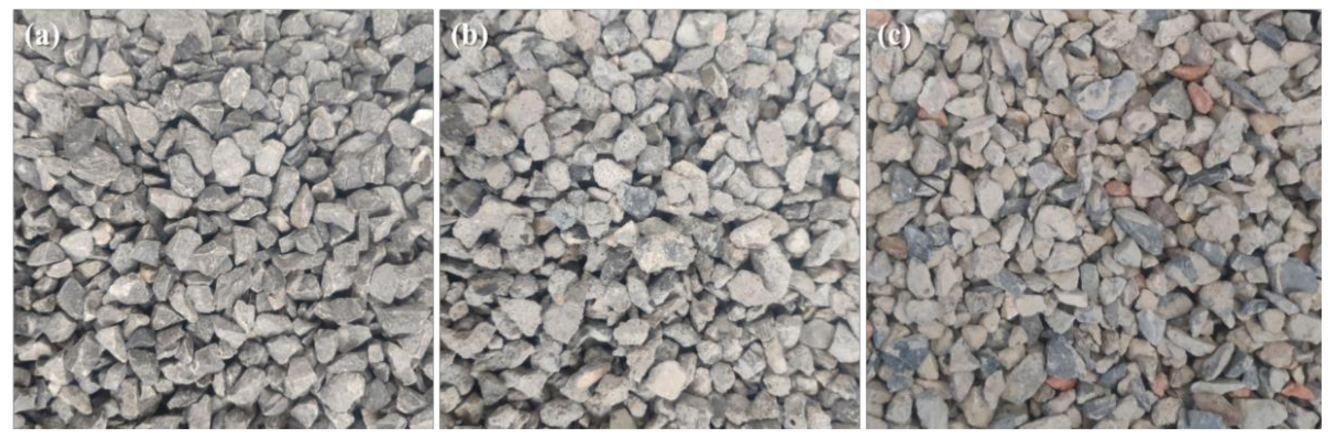

Figure 1. Macro photographs of three types of aggregate: (a) NA; (b) $\mathrm{RCA}_{1}$; and (c) $\mathrm{RCA}_{2}$.

\subsection{Preparation Process of IRPC}

In this study, five different replacement rates, $0 \%, 25 \%, 50 \%, 75 \%$ and $100 \%$, were used by replacing NA with RCA. The mix proportions of the used innovative pervious 
concrete specimens are listed in Table 3. Because the three types of aggregate used have different apparent densities and water absorptions, NA was replaced by RCA with the volume fraction under the same $\mathrm{w} / \mathrm{c}$ ratio, and the additional water was added to ensure the workability of IRPC. Cube samples, with the dimensions $150 \times 150 \times 150 \mathrm{~mm}^{3}$, were cast for compressive strength, mass loss, abrasion resistance and sulfate wetting-drying tests. The preparation process of IRPC is shown in Figure 2. Firstly, IRPC was prepared by the two-stage mixing approach, which could improve its compressive strength and reduce its strength variability [28]. The coarse and fine aggregates and half of the water were mixed for $60 \mathrm{~s}$ and then the binding materials, composed of cement, FA and SF, were added and mixed for $30 \mathrm{~s}$, and finally, the remaining half of the water and SP were added and mixed for $120 \mathrm{~s}$. Then the concrete mixtures were poured into the special molds that were perforated beforehand and with steel rods inserted into the reserved holes. The detailed schematic diagram of the pore distribution is shown in Figure 3. The gray area in Figure 3 is the actual wear area, and all pores are ensured to be in the wear area. The diameter of the used steel rod is $3 \mathrm{~mm}$, and these steel rods would be pulled out after the initial setting of the IRPC. Finally, the IRPC was demolded after $24 \mathrm{~h}$ and preserved in the standard curing room $\left(20 \pm 2{ }^{\circ} \mathrm{C}, \mathrm{RH} \geq 95 \%\right)$ for $28 \mathrm{~d}$.

Table 3. Mixture proportions of innovative pervious concrete specimens $\left(\mathrm{kg} / \mathrm{m}^{3}\right)$.

\begin{tabular}{|c|c|c|c|c|c|c|c|c|c|}
\hline $\begin{array}{c}\text { Concrete } \\
\text { Types }\end{array}$ & NA & RCA & Sand & Cement & FA & SF & SP & Water & Additional Water \\
\hline INPC & 1102 & 0 & 962 & 428 & 53 & 53 & 5.3 & 248 & 0 \\
\hline $\begin{array}{c}\text { IRPC }_{1-25} \\
\text { IRPC }_{1-50} \\
\text { IRPC }_{1-75} \\
\text { IRPC }_{1-100}\end{array}$ & $\begin{array}{c}827 \\
551 \\
276 \\
0\end{array}$ & $\begin{array}{c}267 \\
535 \\
802 \\
1069\end{array}$ & $\begin{array}{l}962 \\
962 \\
962 \\
962\end{array}$ & $\begin{array}{l}428 \\
428 \\
428 \\
428\end{array}$ & $\begin{array}{l}53 \\
53 \\
53 \\
53\end{array}$ & $\begin{array}{l}53 \\
53 \\
53 \\
53\end{array}$ & $\begin{array}{l}5.3 \\
5.3 \\
5.3 \\
5.3\end{array}$ & $\begin{array}{l}248 \\
248 \\
248 \\
248\end{array}$ & $\begin{array}{l}3.5 \\
7.0 \\
10.4 \\
13.9\end{array}$ \\
\hline $\begin{array}{l}\text { IRPC }_{2-25} \\
\text { IRPC }_{2-50} \\
\text { IRPC }_{2-75} \\
\text { IRPC }_{2-100}\end{array}$ & $\begin{array}{c}827 \\
551 \\
276 \\
0\end{array}$ & $\begin{array}{c}259 \\
519 \\
778 \\
1037\end{array}$ & $\begin{array}{l}962 \\
962 \\
962 \\
962\end{array}$ & $\begin{array}{l}428 \\
428 \\
428 \\
428\end{array}$ & $\begin{array}{l}53 \\
53 \\
53 \\
53\end{array}$ & $\begin{array}{l}53 \\
53 \\
53 \\
53\end{array}$ & $\begin{array}{l}5.3 \\
5.3 \\
5.3 \\
5.3\end{array}$ & $\begin{array}{l}248 \\
248 \\
248 \\
248\end{array}$ & $\begin{array}{l}12.5 \\
24.9 \\
37.4 \\
49.8\end{array}$ \\
\hline
\end{tabular}

INPC: Innovative natural pervious concrete; IRPC: Innovative recycled pervious concrete; NA: Natural aggregate RCA: Recycled coarse aggregate; FA: Fly ash; SF: Silica fume; SP: Polycarboxylate type superplasticizer.

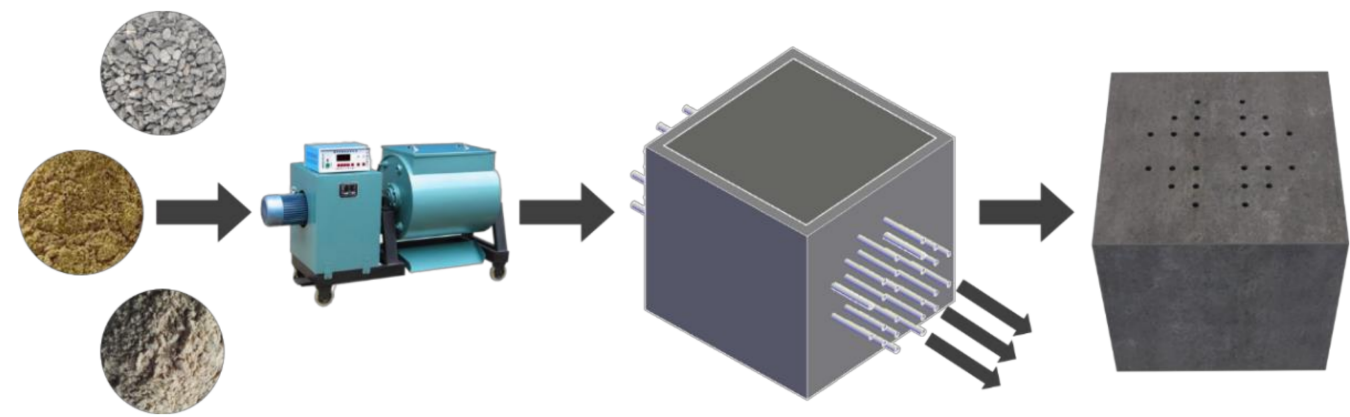

Figure 2. Schematic diagram of the preparation process of IRPC.

\subsection{Testing Procedures}

\subsubsection{Coarse Aggregate Property}

The properties of the three types of aggregate used were measured by ASTM C33 [29] and the Chinese standard GB/T 25177-2010 [30].

\subsubsection{Permeability}

The performance of pervious concrete was characterized by the permeability coefficient. The innovative pervious concrete used in the present study was measured by the constant-head method according to the Chinese standard CJJ/T 135-2009 [31]. The permeability coefficient was determined by the following Equation (1): 


$$
\mathrm{K}=\frac{\mathrm{Q} \cdot \mathrm{L}}{\mathrm{A} \cdot \mathrm{H} \cdot \mathrm{t}}
$$

where: $\mathrm{K}$ is the permeability coefficient, in $\mathrm{mm} / \mathrm{s}$; $\mathrm{Q}$ is the amount of water flowing out of the outlet in $\mathrm{t}$ seconds, in $\mathrm{mm}^{3}$; $\mathrm{L}$ is the thickness of test specimen, in $\mathrm{mm}$; $\mathrm{A}$ is the area of the top surface of the test specimen, in $\mathrm{mm}^{2} ; \mathrm{H}$ is the difference between the internal and external head, in $\mathrm{mm}$.

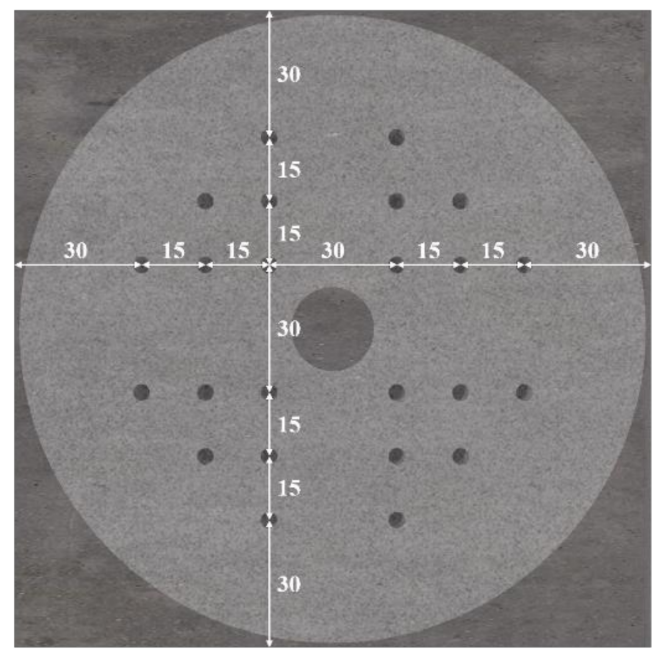

Figure 3. Schematic diagram of the pore distribution.

\subsubsection{Compressive Strength}

The compressive strength test of INPC and IRPC was performed according to ASTM C109 [32].

\subsubsection{Abrasion Resistance}

The abrasion resistance was tested according to the Chinese standard JC/T 4212004 [33]. The abrasion resistance of specimens is defined by abrasion loss per unit area. Abrasion loss per unit area is calculated according to the following Equation (2):

$$
\mathrm{G}=\frac{\mathrm{m}_{1}-\mathrm{m}_{2}}{0.0125}
$$

where: $\mathrm{G}$ is the abrasion loss per unit area, in $\mathrm{kg} / \mathrm{m}^{2} ; \mathrm{m}_{1}$ is the mass of the specimen before abrasion, in $\mathrm{kg} ; \mathrm{m}_{2}$ is the mass of the specimen after abrasion, in $\mathrm{kg} ; 0.0125$ is the area of the abrasion area.

\subsubsection{Sulfate Wetting-Drying Test}

The sulfate wetting-drying test was carried out according to the Chinese standard GB/T 50082-2009 [34]. A wetting-drying cycle of $24 \mathrm{~h}$ consisted of the following four steps. The IRPC specimens were immersed in a $5 \%$ (by wt\%) sodium sulfate $\left(\mathrm{Na}_{2} \mathrm{SO}_{4}\right)$ solution for $15 \mathrm{~h}$, followed by air drying for $1 \mathrm{~h}$, drying for $6 \mathrm{~h}$ at $80^{\circ} \mathrm{C}$ and finally by air cooling for $2 \mathrm{~h}$. Sulfate wetting-drying cycles ranged from 0 , to 30 to 60 days.

\subsubsection{SEM Analysis}

The microstructures of IRPC were characterized by SEM. SEM analysis was performed by a Zeiss SUPRA55 scanning electron microscope to focus on the ITZ of IRPC.

\section{Results and Discussion}

\subsection{Compressive Strength}

The compressive strength of IRPC with variable replacement rates $(0 \%, 25 \%, 50 \%$, $75 \%$ and $100 \%)$ after different sulfate wetting-drying cycles $(0,30$ and 60$)$ was displayed in 
Figure 4. It can be found that the initial compressive strength of IRPC was excellent. The compressive strength of all groups of IRPC before sulfate attack was more than $40 \mathrm{MPa}$. After 30 sulfate wetting-drying cycles, the compressive strength of most groups of IRPC increased slightly, except in the case of $100 \%$ replacement with $\mathrm{RCA}_{2}$. The possible reason for this phenomenon is that the hydration reaction of the IRPC matrix was still going on at the initial stage of the sulfate wetting-drying cycle [35]. The secondary hydration products improved the compactness and strength of the IRPC. In addition, the high-temperature drying of the wetting-drying cycles could also promote the hydration reaction of the IRPC matrix [36]. When sulfate enters the concrete, the erosion products, such as gypsum and ettringite, will be generated, and these erosion products will accumulate in the pores and cracks of IRPC, especially in its ITZ [37]. However, at the initial stage of sulfate wetting-drying cycles, the erosion products can fill up the pores and cracks and improve the compactness of IRPC. Therefore, the compressive strength of IRPC increased slightly after 30 sulfate wetting-drying cycles. However, due to the poor performance of $\mathrm{RCA}_{2}$ and its weak ITZ, the compressive strength of IRPC 2 with a $100 \%$ replacement rate decreased slightly after 30 cycles, but the reduction was very small. This indicates that the reduction in strength due to the utilization of RCA is playing the leading role. On the whole, secondary hydration and filling of sulfate erosion products can slightly increase the compressive strength of IRPC at the early stage of sulfate wetting-drying cycles.

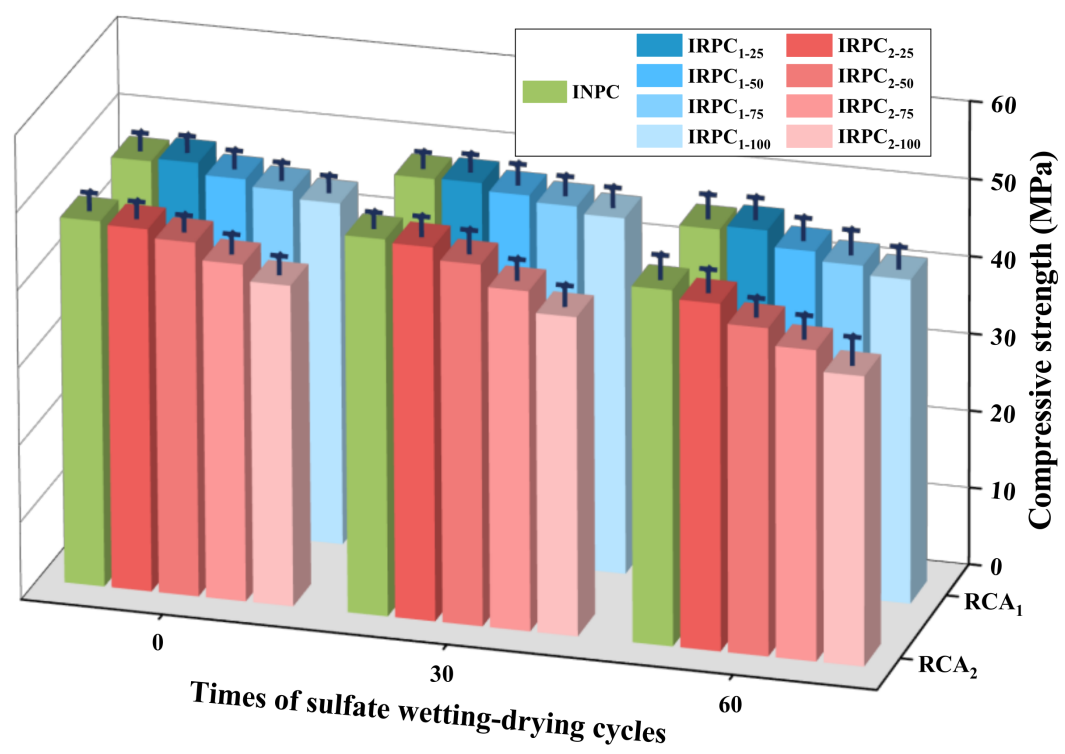

Figure 4. Compressive strength of IRPC with variable replacement rates after different sulfate wetting-drying cycles.

After 60 sulfate wetting-drying cycles, the compressive strength decreased compared with its initial compressive strength. It is worth noting that the decline of compressive strength increased with the growth of the replacement rate. This is because the positive effects mentioned above had peaked when the wetting-drying cycles increased. The volume of sulfate erosion products expanded further, and cracks occurred in the IRPC matrix, especially in ITZ, resulting in the decline of strength. To sum up, the change of compressive strength under sulfate attack can be divided into a strengthening stage and a degradation stage.

Another point of concern is that there was little difference between IRPC ${ }_{1-25}$ and INPC in sulfate resistance at the $25 \% \mathrm{RCA}_{1}$ replacement rate. $\mathrm{IRPC}_{1-25}$ even had a slightly higher compressive strength than INPC. This might be on account of the good properties of $\mathrm{RCA}_{1}$, and appropriately attached mortar provided space for the accumulation of sulfate corrosion products. Therefore, the appropriate addition of high-quality RCA will have a positive effect on the sulfate resistance of concrete. 


\subsection{Permeability}

According to our former research [13], the matrix of the innovative pervious concrete has a very low porosity; its permeability mainly depends on the reserved top-bottom interconnected pores. Therefore, its permeability coefficient is almost entirely determined by the size and distribution of the pores and has little relationship with the mix proportion. The advantage is that the permeability coefficient of IRPC is higher and more controllable than traditional pervious concrete. The permeability coefficients of IRPC under abrasion and sulfate attack were revealed in Figure 5 . The permeability coefficients of all groups were about $7 \mathrm{~mm} / \mathrm{s}$, much higher than the minimum requirement of pervious concrete $(0.5 \mathrm{~mm} / \mathrm{s})$. With the increase of sulfate wetting-drying cycles, the permeability coefficients of IRPC slightly reduced. This may be due to the slight expansion of IRPC's volume after sulfate attack [38], leading to the reduction of its pore volume and permeability coefficients. Moreover, it can be found that the abrasion slightly reduced the permeability of IRPC. This is caused by the accumulation of debris in the pores from abrasion, but the reduction in the permeability coefficient is quite slight. Compared with the top-bottom interconnected pores of IRPC, the zigzag pores of traditional pervious concrete are more likely to be clogged by debris accumulation [39], resulting in the decline of permeability.

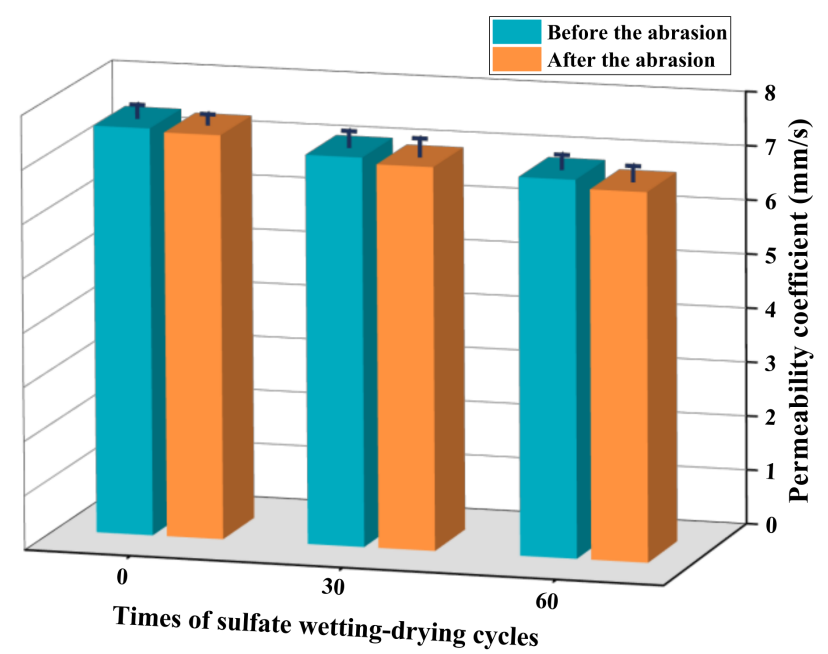

Figure 5. Permeability coefficients of IRPC before and after the abrasion after different sulfate wetting-drying cycles.

Traditional pervious concrete cannot guarantee both strength and permeability performance. Lu et al. [22] prepared recycled pervious concrete using waste glass and RCA. When NA was fully replaced by RCA, the compressive strength and permeability coefficient of recycled pervious concrete are about $20 \mathrm{MPa}$ and $2.3 \mathrm{~mm} / \mathrm{s}$, respectively. When using $50 \%$ waste glass cullet and 50\% RCA as aggregates, the compressive strength of recycled pervious concrete increased to $22 \mathrm{MPa}$, but the permeability coefficient was reduced to $1.2 \mathrm{~mm} / \mathrm{s}$. IRPC can possess the compressive strength of $40 \mathrm{MPa}$ and the permeability coefficient of $7 \mathrm{~mm} / \mathrm{s}$ even at a $100 \%$ replacement rate. Therefore, in terms of the strength and permeability performance, the combined use of innovative pervious concrete as the matrix and RCA as the aggregate is attractive and promising to produce IRPC with good strength and permeability.

\subsection{Mass Loss}

The mass-loss rates of INPC and IRPC specimens are revealed in Figure 6. It can be clearly observed that the mass of all specimens increased firstly and then gradually decreased with the increasing number of wetting-drying cycles. This is because the generation of sulfate erosion and hydration products increased the mass [40], and with the continuous accumulation of these products, a huge expansion force is generated inside of IRPC. 
Then micro-cracks and angle loss occurred in IRPC, which made the mass decrease [41]. These two stages correspond well with the two stages present in compressive strength. Moreover, the fluctuation range of mass change also becomes larger with the increase of wetting-drying cycles. The reason for this phenomenon is that with the growth of the replacement rate, there was more space for corrosion products to accumulate in IRPC, and the compactness of IRPC decreased, which accelerated the generation and accumulation of sulfate erosion products.

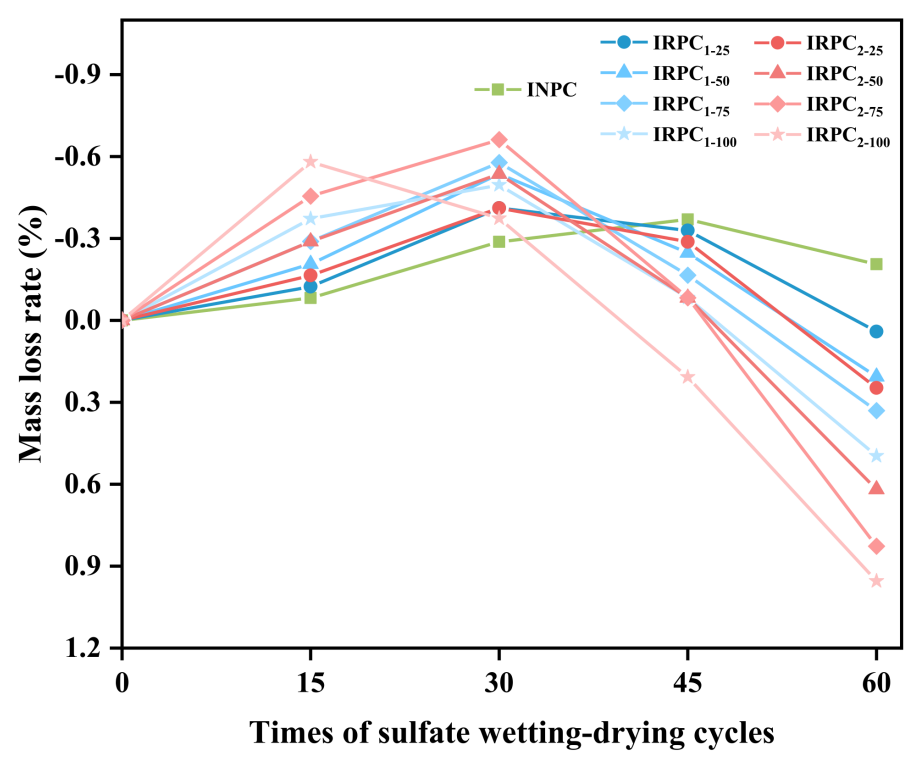

Figure 6. Mass-loss rate of IRPC with variable replacement rates after different sulfate wettingdrying cycles.

\subsection{Abrasion Resistance}

Since the surface layer of the concrete is made up almost entirely of cement mortar, only when the grinding is carried out to a certain extent, the aggregate inside will be ground. The purpose of this study is to explore the effect of aggregate grades and replacement rate on abrasion resistance. Therefore, abrasion resistance is divided into two parts, the surface layer and the internal layer, for analysis. First, IRPC was ground for 30 cycles to explore the abrasion resistance of the surface layer and then IRPC was continued to be ground for 40 cycles to explore the abrasion resistance of the internal layer.

\subsubsection{Surface Layer}

Figure 7 displays the abrasion loss per unit area on the surface layer of IRPC with five replacement rates under sulfate attack. It is clearly reflected in Figure 7 that the abrasion loss per unit area of the specimens decreased after 30 sulfate wetting-drying cycles but increased significantly after 60 wetting-drying cycles, except for the specimens with $75 \%$ and $100 \% \mathrm{RCA}_{2}$ replacement rates. This is because the sulfate erosion products produced in the early stage of sulfate attack had the filling effect on the pores and cracks of the specimen [42]. In addition, the secondary hydration reaction occurred and improved the strength of the specimen [43]. Therefore, the compactness and abrasion resistance of the surface layer were enhanced. After 60 wetting-drying cycles, the volume of sulfate erosion products accumulated inside the specimens expanded, resulting in micro-cracks in the specimens. The expansion stress made the surface mortar become brittle, resulting in a decline in abrasion resistance. 


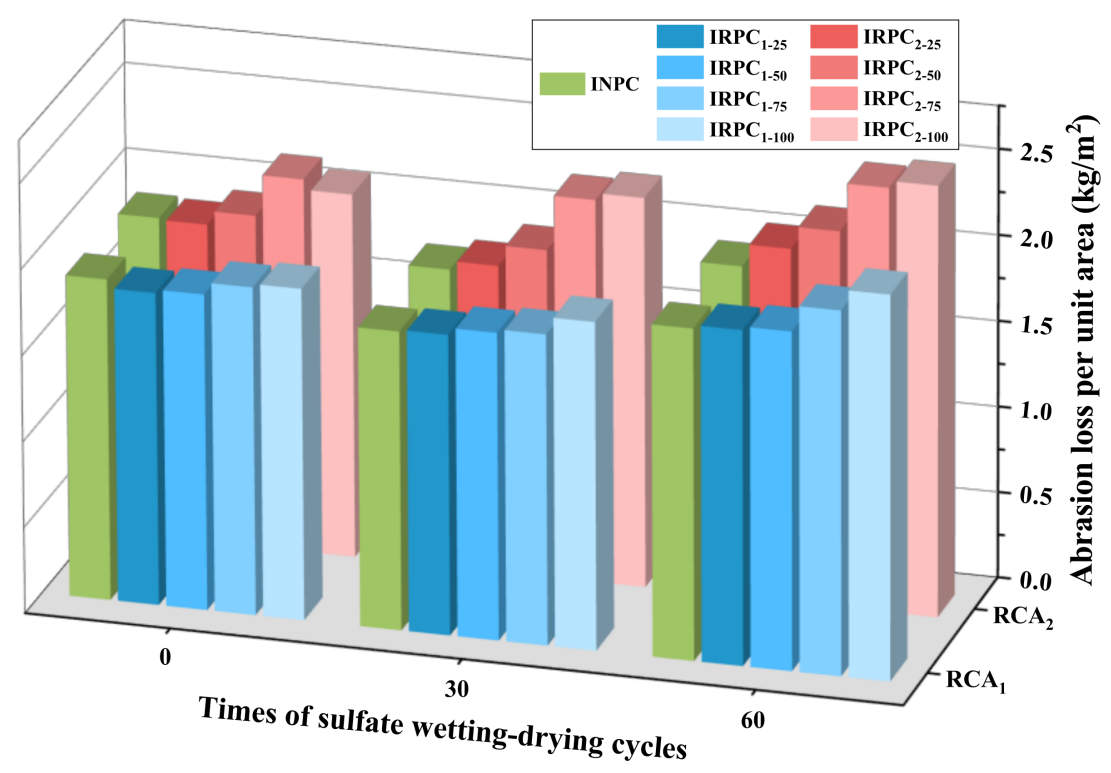

Figure 7. Abrasion loss per unit area on the surface layer of IRPC with variable replacement rates after different sulfate wetting-drying cycles.

\subsubsection{Internal Layer}

The abrasion loss per unit area on the internal layer of different IRPC under sulfate attack is shown in Figure 8. The abrasion resistance of the internal layer was different from that of the surface layer. When the replacement rate is greater than $25 \%$, the abrasion loss per unit area of IRPC increases with the increase of the replacement rate and the number of wetting-drying cycles. Therefore, it can be seen that the influence of aggregate grades and replacement rate on the abrasion resistance of the internal layer of IRPC was more significant than that of the surface layer. This is because the surface layer was mainly the compact mortar layer on the specimen surface, while the inner layer contained weak links, such as RCA, attached mortar and ITZ. Sulfate erosion products mainly accumulated and expanded from the ITZ inside the specimen, which could easily affect the abrasion resistance of the internal layer.

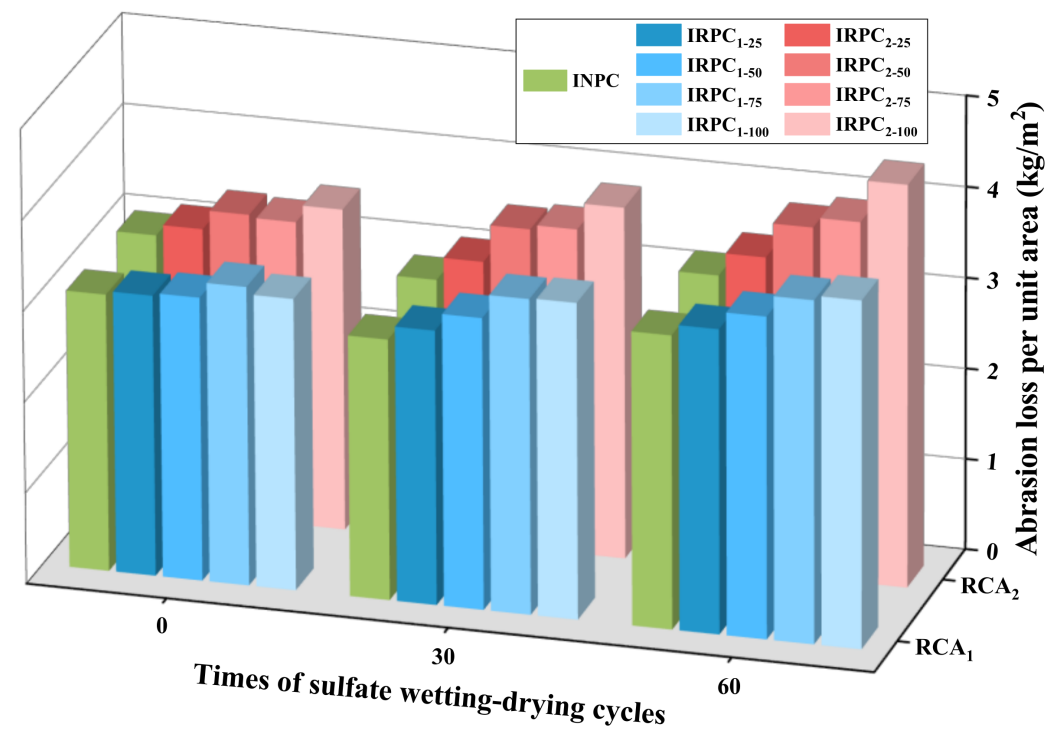

Figure 8. Abrasion loss per unit area on the internal layer of IRPC with variable replacement rates after different sulfate wetting-drying cycles. 


\subsection{SEM Analysis}

To further investigate the effect of the aggregates' quality grades on the sulfate attack mechanism of IRPC, an SEM analysis on the ITZ of IRPC was carried out. Figure 9 shows the SEM images of the IRPC prepared from three kinds of aggregates with different quality grades. First of all, Figure 9(a1,a2) displayed the ITZ of INPC before and after the sulfate attack. As can be seen in Figure 9(a1), the initial ITZ of INPC was relatively smooth, and no obvious cracks and pores were observed in the paste. After the sulfate attack, the ITZ of INPC expanded slightly and widened, as shown in Figure 9(a2). The little white spots on the ITZ were the erosion products, which were small in volume. NA possessed the best properties and was regarded as the high-quality RCA. Therefore, INPC prepared from NA possessed the best compressive strength, abrasion resistance and sulfate resistance, which was consistent with the results obtained in macroscopic experiments.
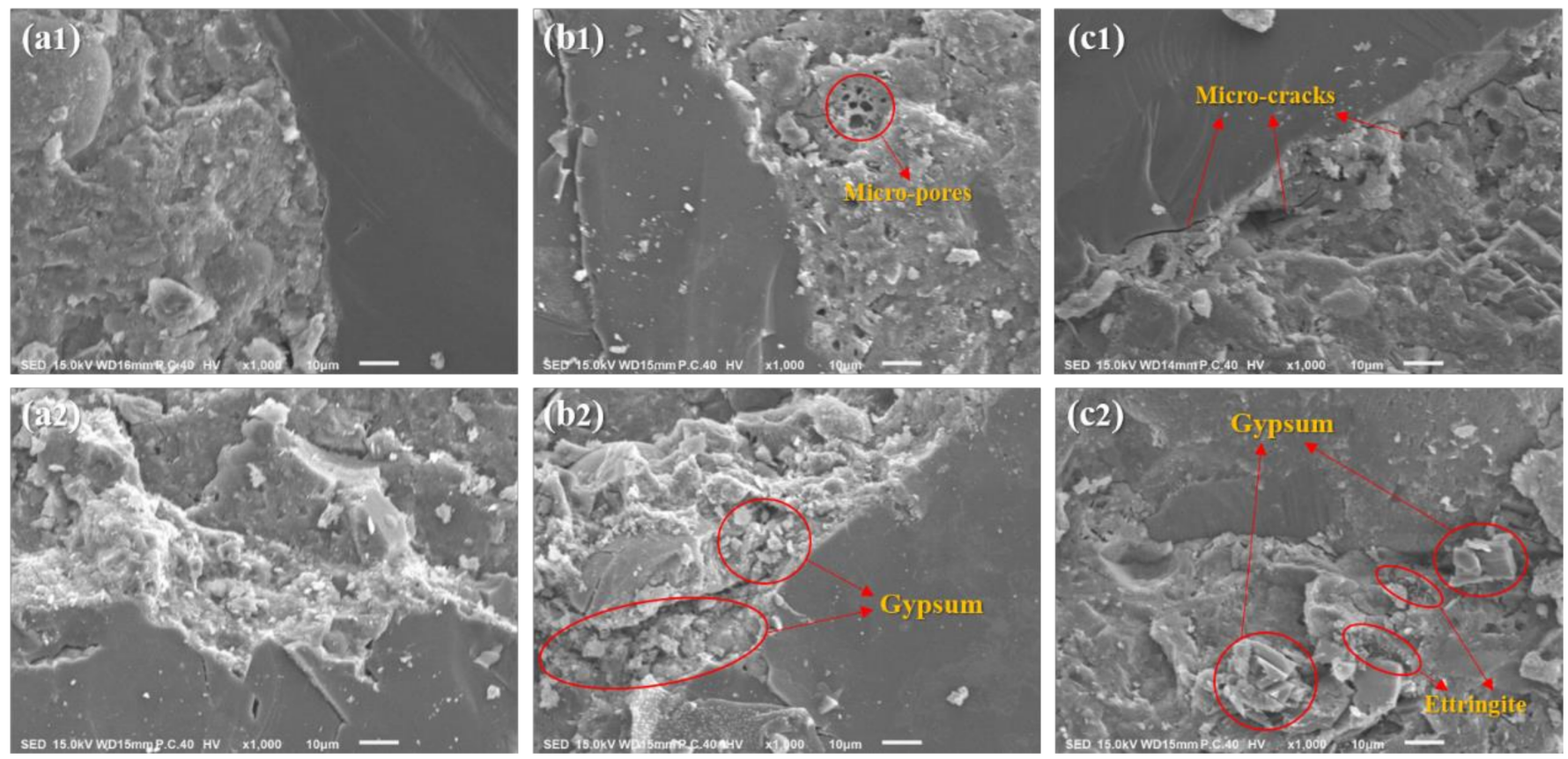

Figure 9. SEM images of (a1) INPC, (b1) IRPC $1-100$ and (c1) IRPC $2-100$ before sulfate attack, and (a2) INPC, (b2) IRPC $1-100$ and (c2) IRPC 2-100 after 60 sulfate wetting-drying cycles.

In addition, the SEM images of $\mathrm{IRPC}_{1}$ prepared from the medium quality of $\mathrm{RCA}_{1}$ were revealed in Figure 9(b1,b2). Figure 9(b1) showed that the initial ITZ of IRPC 1 was slightly undulating and uneven, and there were some micro pores in the paste of $\mathrm{IRPC}_{1}$. After sulfate wetting-drying cycles, the short columnar crystals of gypsum [44] were observed in the ITZ of IRPC 1 in Figure 9(b2). The formation of erosion products, such as gypsum, further expanded the volume of the ITZ and reduced its bonding strength [45], which had an adverse effect on the mechanical properties and abrasion resistance of IRPC.

Finally, Figure 9(c1,c2) showed the SEM images of IRPC 2 prepared from the low quality of $\mathrm{RCA}_{2}$. As shown in Figure 9(c1), the initial ITZ of IRPC 2 was rough and uneven on the surface with a straight crack in it. After sulfate attack, large columnar crystals of gypsum and needle-like phase crystals of ettringite [46] were observed in Figure 9(c2). The massive sulfate erosion products made the ITZ expand rapidly in volume and become loose. The ITZ of IRPC 2 was the most cracked and loosest after the sulfate attack. The compressive strength and abrasion resistance of $\mathrm{IRPC}_{2}$ were the worst among all three types. This was because that the quality grade of $\mathrm{RCA}_{2}$ was the low-grade, indicating a large amount of attached mortar was attached to the surface of $\mathrm{RCA}_{2}$. The new ITZ formed between the old attached mortar and the new mortar had a low bonding strength and a large number of cracks and pores [47]. Therefore, after sulfate attack, erosion products 
tended to accumulate in these cracks and pores. The volume of sulfate erosion products gradually expanded and made the weak ITZ more fragmented [48], resulting in a further reduction in the strength of $I_{R P C}$.

However, the accumulation of these sulfate erosion products was not all negative. When the replacement rate of RCA was low, and the quality of RCA was better (attached mortar content of RCA is low), the sulfate erosion products could fill the micro pores and cracks in the ITZ and even in the attached mortar of RCA. This filling effect could improve the compactness of IRPC; thus, improving its strength and abrasion resistance. This phenomenon was consistent with what was observed in the macroscopic experiment.

\section{Conclusions}

In this study, the mechanical properties, permeability and abrasion resistance of innovative recycled pervious concrete (IRPC) with three RCA quality grades and five replacement rates under sulfate attack was investigated. Based on the experimental results and microscopic analysis, the following conclusions can be drawn:

- IRPC can not only reach a higher compressive strength but also meet a higher permeability coefficient at the same time, even at a 100\% replacement rate. After 60 sulfate wetting-drying cycles, the compressive strength and permeability coefficient of IRPC slightly decreased. With the increase of the replacement rate and the decrease of aggregate quality, their drops continued to increase. However, overall, the decline of compressive strength and permeability coefficient of IRPC was modest, representing the sulfate resistance of IRPC was fine.

- The abrasion resistance of IRPC was mainly influenced by the RCA replacement rate. The abrasion loss of IRPC increased with the increase of the replacement rate. Yet, up to a $50 \%$ RCA replacement rate could be adopted without significantly affecting the abrasion resistance of IRPC. However, when the RCA quality grade was high (attached mortar content $<25 \%$ ), this threshold replacement rate can be increased to $100 \%$.

- The influence of sulfate attack on the compressive strength and abrasion resistance of IRPC could be divided into two stages. The first stage was the enhancement or slow declining stage. In this stage, the sulfate erosion products could fill the micro pores and cracks in the ITZ and the attached mortar. This filling effect could improve the compactness of IRPC; thus, improving its strength and abrasion resistance. The next stage was the declining stage. In this stage, the volume of sulfate erosion products gradually expanded and made the ITZ and matrix of IRPC loose and fragmented, resulting in a reduction in the strength and abrasion resistance of IRPC.

The experimental results, in terms of compressive strength, permeability and abrasion resistance, show that IRPC made with even 100\% RCA was acceptable under sulfate attack. When the replacement rate was less than $50 \%$, the performance of IRPC was very close to that of INPC. With the improvement of RCA quality, this threshold replacement rate could be further increased. The existing traditional pervious concrete can only be used in applications with low abrasive forces. However, IRPC can be used for applications with medium or even high abrasive forces, which greatly expands the application range of pervious concrete.

Author Contributions: Conceptualization, M.H. and H.L.; Data curation, M.H. and B.C.; Formal analysis, B.C. and C.C.; Funding acquisition, H.L. and P.Z.; Investigation, B.C. and X.W.; Methodology, P.Z.; Project administration, B.C. and H.L.; Resources, Y.L. and H.L.; Supervision, P.Z.; Validation, M.H., Y.L. and H.L.; Visualization, M.H.; Writing—original draft, M.H.; Writing—review and editing, M.H. and H.L. All authors have read and agreed to the published version of the manuscript.

Funding: This research was funded by the National Natural Science Foundation of China, grant number 51878081.

Institutional Review Board Statement: Not applicable. 
Informed Consent Statement: Not applicable.

Data Availability Statement: Not applicable.

Acknowledgments: This research is also financial supported by State Key Laboratory of Silicate Materials for Architectures (Wuhan University of Technology), grant number SYSJJ2020-14.

Conflicts of Interest: The authors declare no conflict of interest.

\section{References}

1. Zheng, Y.; Zhuo, J.; Zhang, P. A review on durability of nano-SiO 2 and basalt fiber modified recycled aggregate concrete. Constr. Build. Mater. 2021, 304, 124659. [CrossRef]

2. Chan, R.; Liu, X.; Galobardes, I. Parametric study of functionally graded concretes incorporating steel fibres and recycled aggregates. Constr. Build. Mater. 2020, 242, 118186. [CrossRef]

3. Revilla-Cuesta, V.; Skaf, M.; Santamaría, A.; Ortega-López, V.; Manso, J.M. Assessment of longitudinal and transversal plastic behavior of recycled aggregate self-compacting concrete: A two-way study. Constr. Build. Mater. 2021, 292, 123426. [CrossRef]

4. Sahraei Moghadam, A.; Omidinasab, F.; Abdalikia, M. The effect of initial strength of concrete wastes on the fresh and hardened properties of recycled concrete reinforced with recycled steel fibers. Constr. Build. Mater. 2021, 300, 124284. [CrossRef]

5. Silva, R.V.; de Brito, J.; Dhir, R.K. Establishing a relationship between modulus of elasticity and compressive strength of recycled aggregate concrete. J. Clean. Prod. 2016, 112, 2171-2186. [CrossRef]

6. Zhu, P.; Hua, M.; Liu, H.; Wang, X.; Chen, C. Interfacial evaluation of geopolymer mortar prepared with recycled geopolymer fine aggregates. Constr. Build. Mater. 2020, 259, 119849. [CrossRef]

7. Rockson, C.; Tamanna, K.; Shahria Alam, M.; Rteil, A. Effect of rebar embedment length on the bond behavior of commercially produced recycled concrete using beam-end specimens. Constr. Build. Mater. 2021, 286, 122957. [CrossRef]

8. Lo, F.-C.; Lee, M.-G.; Lo, S.-L. Effect of coal ash and rice husk ash partial replacement in ordinary Portland cement on pervious concrete. Constr. Build. Mater. 2021, 286, 122947. [CrossRef]

9. Elizondo-Martínez, E.-J.; Andrés-Valeri, V.-C.; Jato-Espino, D.; Rodriguez-Hernandez, J. Review of porous concrete as multifunctional and sustainable pavement. J. Build. Eng. 2020, 27, 100967. [CrossRef]

10. Shabalala, A.N.; Ekolu, S.O.; Diop, S.; Solomon, F. Pervious concrete reactive barrier for removal of heavy metals from acid mine drainage-Column study. J. Hazard. Mater. 2017, 323, 641-653. [CrossRef]

11. Bhutta, M.A.R.; Tsuruta, K.; Mirza, J. Evaluation of high-performance porous concrete properties. Constr. Build. Mater. 2012, 31, 67-73. [CrossRef]

12. Vázquez-Rivera, N.I.; Soto-Pérez, L.; St John, J.N.; Molina-Bas, O.I.; Hwang, S.S. Optimization of pervious concrete containing fly ash and iron oxide nanoparticles and its application for phosphorus removal. Constr. Build. Mater. 2015, 93, 22-28. [CrossRef]

13. Feng, J.; Zong, N.; Zhu, P.; Liu, H.; Yao, L.; Geng, J. The Frost-resisting Durability of High Strength Self-Compacting Pervious Concrete in Deicing Salt Environment. J. Wuhan Univ. Technol. Sci. Ed. 2020, 35, 167-175. [CrossRef]

14. Zhu, P.; Hao, Y.; Liu, H.; Wang, X.; Gu, L. Durability evaluation of recycled aggregate concrete in a complex environment. J. Clean. Prod. 2020, 273, 122569. [CrossRef]

15. Saberian, M.; Li, J. Investigation of the mechanical properties and carbonation of construction and demolition materials together with rubber. J. Clean. Prod. 2018, 202, 553-560. [CrossRef]

16. Kazmi, S.M.S.; Munir, M.J.; Wu, Y.-F.; Patnaikuni, I.; Zhou, Y.; Xing, F. Effect of different aggregate treatment techniques on the freeze-thaw and sulfate resistance of recycled aggregate concrete. Cold Reg. Sci. Technol. 2020, 178, 103126. [CrossRef]

17. Vieira, G.L.; Schiavon, J.Z.; Borges, P.M.; da Silva, S.R.; de Oliveira Andrade, J.J. Influence of recycled aggregate replacement and fly ash content in performance of pervious concrete mixtures. J. Clean. Prod. 2020, 271, 122665. [CrossRef]

18. Gonçalves, T.; Silva, R.V.; de Brito, J.; Fernández, J.M.; Esquinas, A.R. Mechanical and durability performance of mortars with fine recycled concrete aggregates and reactive magnesium oxide as partial cement replacement. Cem. Concr. Compos. 2020, 105, 103420. [CrossRef]

19. Peng, Q.; Wang, L.; Lu, Q. Influence of recycled coarse aggregate replacement percentage on fatigue performance of recycled aggregate concrete. Constr. Build. Mater. 2018, 169, 347-353. [CrossRef]

20. Zhu, P.; Hao, Y.; Liu, H.; Wei, D.; Liu, S.; Gu, L. Durability evaluation of three generations of $100 \%$ repeatedly recycled coarse aggregate concrete. Constr. Build. Mater. 2019, 210, 442-450. [CrossRef]

21. Zhang, J.-Y.; Xing, Y.-Y.; Wang, Q.-W.; Zhang, N.; Deng, W.; Gao, E.-Q. Two new CuI compounds with zwitterionic tetrazolate ligand: In situ synthesis, crystal structures, luminescence and photocatalytic properties. J. Solid State Chem. 2015, $232,19-25$. [CrossRef]

22. Lu, J.-X.; Yan, X.; He, P.; Poon, C.S. Sustainable design of pervious concrete using waste glass and recycled concrete aggregate. J. Clean. Prod. 2019, 234, 1102-1112. [CrossRef]

23. El-Hassan, H.; Kianmehr, P.; Zouaoui, S. Properties of pervious concrete incorporating recycled concrete aggregates and slag Constr. Build. Mater. 2019, 212, 164-175. [CrossRef]

24. Ma, H.; Gong, W.; Yu, H.; Sun, W. Durability of concrete subjected to dry-wet cycles in various types of salt lake brines. Constr. Build. Mater. 2018, 193, 286-294. [CrossRef] 
25. Bagheri, A.; Ajam, A.; Zanganeh, H. Investigation of chloride ingress into concrete under very early age exposure conditions. Constr. Build. Mater. 2019, 225, 801-811. [CrossRef]

26. Xie, F.; Li, J.; Zhao, G.; Wang, C.; Wang, Y.; Zhou, P. Experimental investigations on the durability and degradation mechanism of cast-in-situ recycled aggregate concrete under chemical sulfate attack. Constr. Build. Mater. 2021, 297, 123771. [CrossRef]

27. Sarkar, S.; Mahadevan, S.; Meeussen, J.C.L.; van der Sloot, H.; Kosson, D.S. Numerical simulation of cementitious materials degradation under external sulfate attack. Cem. Concr. Compos. 2010, 32, 241-252. [CrossRef]

28. Tam, V.W.Y.; Gao, X.F.; Tam, C.M. Microstructural analysis of recycled aggregate concrete produced from two-stage mixing approach. Cem. Concr. Res. 2005, 35, 1195-1203. [CrossRef]

29. ASTM C33/C33M-18. Standard Specification for Concrete Aggregates; ASTM International: West Conshohocken, PA, USA, 2018.

30. GB/T 25177-2010. Recycled Coarse Aggregate for Concrete. Beijing, China. 2010. Available online: http://codeofchina.com/ standard/GBT25177-2010.html (accessed on 1 September 2021).

31. CJJ/T 135-2009. Technical Specification for Pervious Cement Conerete Pavement. Beijing, China. 2009. Available online: https://www. chinesestandard.net/PDF/English.aspx/CJJT135-2009 (accessed on 1 September 2021).

32. ASTM C109/C109M-20a. Standard Test. Method for Compressive Strength of Hydraulic Cement Mortars (Using 2-in. or [50-mm] Cube Specimens); ASTM International: West Conshohocken, PA, USA, 2020.

33. JC/T 421-2004. Method of Wear Abrasion for Harden Mortar. Beijing, China. 2004. Available online: https://www.chinesestandard. net/PDF/English.aspx/JCT421-2004 (accessed on 1 September 2021).

34. GB/T 50082-2009. Standard for Test. Methods of Long-Term Performance and Durability of Ordinary Concrete. Beijing, China. 2009. Available online: https://www.standardsofchina.com/standard/GBT50082-2009 (accessed on 1 September 2021).

35. Yu, X.; Chen, D.; Feng, J.; Zhang, Y.; Liao, Y. Behavior of mortar exposed to different exposure conditions of sulfate attack. Ocean Eng. 2018, 157, 1-12. [CrossRef]

36. Rozière, E.; Loukili, A.; El Hachem, R.; Grondin, F. Durability of concrete exposed to leaching and external sulphate attacks. Cem. Concr. Res. 2009, 39, 1188-1198. [CrossRef]

37. Liu, K.; Deng, M.; Mo, L. Influence of $\mathrm{pH}$ on the formation of gypsum in cement materials during sulfate attack. Adv. Cem. Res. 2015, 27, 487-493. [CrossRef]

38. Colman, C.; Bulteel, D.; Thiery, V.; Rémond, S.; Michel, F.; Courard, L. Internal sulfate attack in mortars containing contaminated fine recycled concrete aggregates. Constr. Build. Mater. 2021, 272, 121851. [CrossRef]

39. Mata, L.A.; Leming, M.L. Vertical Distribution of Sediments in Pervious Concrete Pavement Systems. ACI Mater. J. 2012, 109, 149-155. [CrossRef]

40. Tang, Z.; Li, W.; Ke, G.; Zhou, J.L.; Tam, V.W.Y. Sulfate attack resistance of sustainable concrete incorporating various industrial solid wastes. J. Clean. Prod. 2019, 218, 810-822. [CrossRef]

41. Zhang, Z.; Jin, X.; Luo, W. Long-term behaviors of concrete under low-concentration sulfate attack subjected to natural variation of environmental climate conditions. Cem. Concr. Res. 2019, 116, 217-230. [CrossRef]

42. Wei, Y.; Chai, J.; Qin, Y.; Li, Y.; Xu, Z.; Li, Y.; Ma, Y. Effect of fly ash on mechanical properties and microstructure of cellulose fiber-reinforced concrete under sulfate dry-wet cycle attack. Constr. Build. Mater. 2021, 302, 124207. [CrossRef]

43. Hisseine, O.A.; Wilson, W.; Sorelli, L.; Tolnai, B.; Tagnit-Hamou, A. Nanocellulose for improved concrete performance: A macro-to-micro investigation for disclosing the effects of cellulose filaments on strength of cement systems. Constr. Build. Mater. 2019, 206, 84-96. [CrossRef]

44. Onuaguluchi, O.; Banthia, N. Long-term sulfate resistance of cementitious composites containing fine crumb rubber. Cem. Concr. Compos. 2019, 104, 103354. [CrossRef]

45. Çakır, Ö. Experimental analysis of properties of recycled coarse aggregate (RCA) concrete with mineral additives. Constr. Build. Mater. 2014, 68, 17-25. [CrossRef]

46. Zhao, G.; Guo, M.; Cui, J.; Li, J.; Xu, L. Partially-exposed cast-in-situ concrete degradation induced by internal-external sulfate and magnesium multiple coupled attack. Constr. Build. Mater. 2021, 294, 123560. [CrossRef]

47. Li, Y.; Yang, X.; Lou, P.; Wang, R.; Li, Y.; Si, Z. Sulfate attack resistance of recycled aggregate concrete with NaOH-solution-treated crumb rubber. Constr. Build. Mater. 2021, 287, 123044. [CrossRef]

48. Dilbas, H.; Şimşek, M.; Çakır, Ö. An investigation on mechanical and physical properties of recycled aggregate concrete (RAC) with and without silica fume. Constr. Build. Mater. 2014, 61, 50-59. [CrossRef] 